Figure Weekly rate of days with services per patient according to switch date

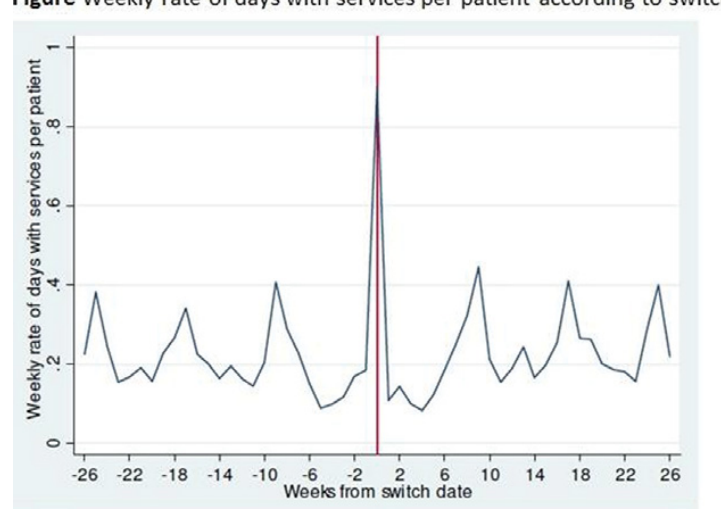

weekly rate of days with services showed no obvious differences before and after the switch but had a clear 8-week pattern (corresponding to the average infusion interval) (Figure).

The total number of services provided was 19,752 (2,019 of these on the switch date). There were significant increases in the rates before vs after switch for 6 of the 16 service categories, although the mean rates were small: telephone consultations (mean rate 1.0 before vs. 1.2 after), patient guidance (0.5 vs. 0.4$)$, intravenous medication ( 0.0 vs. 0.1$)$, clinical controls (2.1 vs. 2.3) and clinical investigations $(0.3$ vs. 0.5$)$, whereas the rate of infliximab treatment decreased (3.1 vs 3.0) (all $p<0.05$, insignificant results not shown).

Conclusions: This analysis showed that there were only small differences in the rates of days with outpatient services and rates of services 6 months before and after the switch from original to biosimilar infliximab. Thus, it is unlikely that the switch is associated with substantially higher cost of health care resources.

References:

[1] Glintborg et al. Arthritis Rheumatol. 2016; 68 (suppl 10).

Disclosure of Interest: B. Glintborg Grant/research support from: Abbvie, J. Sørensen Grant/research support from: Abbvie, M. Hetland Grant/research support from: Orion, BMS, AbbVie, Biogen, Pfizer, MSD

DOI: 10.1136/annrheumdis-2017-eular.3008

\section{THU0649 MANDATORY CHOICE OF FIRST BDMARD IN DENMARK - AN OPPORTUNITY TO STUDY REAL-LIFE EFFECTIVENESS? RESULTS FROM THE DANBIO REGISTRY}

K.L. Grøn ${ }^{1}$, B. Glintborg ${ }^{1}$, M. Nørgaard ${ }^{2}$, F. Mehnert ${ }^{2}$, M. Østergaard ${ }^{1}$, L. Dreyer ${ }^{1}$, N.S. Krogh ${ }^{3}$, M.L. Hetland ${ }^{1} .{ }^{1}$ DANBIO, COPECARE; ${ }^{2}$ Department of Clinical Epidemiology, Aarhus; ${ }^{3}$ Zitelab Aps, Copenhagen, Denmark

Background: In Denmark, biological treatments (bDMARDs) are tax paid. Since year 2013, The Danish Council for the Use of Expensive Hospital Medicines (RADS) has issued recommendations with annual updates regarding RA patients (pts) initiating biological treatment, dictating a mandatory choice of the cheapest bDMARD (1). Furthermore, the percentage of pts expected to be treated according to the RADS recommendation per year is stated. For pts treated with concomitant methotrexate (MTX) recommendations on first line, first choice bDMARD were: Jan 1th 2013-June 30th 2014: certolizumab pegol (in $80 \%$ of pts); July 1th 2014 - June 30th 2015: abatacept (80\%); July 1th 2015-June 30th 2016: biosimilar infliximab (CT-P13) (50\%). The nationwide Danish DANBIO registry collect data prospectively and covers $>90 \%$ of adults with rheumatological diseases treated with bDMARDs in routine care (2).

Objectives: To characterize Danish RA pts initiating first line, first choice treatment with a bDMARD in combination with MTX in the three RADS periods and to explore the degree of compliance to RADS recommendations. Furthermore, to investigate differences in baseline characteristics between those pts who were compliant to RADS guidelines and those who were not.

Methods: For each of the three RADS' periods bio-naive pts with RA were identified in DANBIO and compliance to RADS recommendations was assessed. Baseline characteristics of those who started first choice bDMARD treatment according to RADS were compared with those who started another biologic instead. Comorbidities and previous hospitalized infections were identified in the Danish National Patient Registry. Comorbidities from Charlson Comorbidity Index were summarized except category number 7 , connective tissue disease.

Results: For all three RADS periods, age, gender, functional status and disease activity were typical for pts with RA. Age was median: 57 years, range 18-88 years and disease duration: 3 years, range $0-54$ years. $16-22 \%$ of pts had $\geq 1$ comorbidity and $7-9 \%$ had $\geq 1$ hospitalized infection the previous year. In each of the three RADS periods, $71 \%, 66 \%$ and $60 \%$ of pts followed the RADS recommendations, respectively (Table). The table shows differences between those who started first choice bDMARD treatment according to RADS, and those who did not. Overall, pts who complied to RADS had higher DAS28 and patient VAS global. Characteristics of pts who followed RADS recommendations in the three periods appeared similar.

Conclusions: In this nationwide study of $>600$ RA pts, pts' clinical characteristics
Table 1: Characteristics of RA pts initiating treatment with first bDMARD in combination with MTX stratified by compliance to the recommendations of RADS or not in the three time periods.

\begin{tabular}{|l|c|c|c|c|c|c|}
\hline & \multicolumn{2}{|c|}{$\begin{array}{c}\text { Certolizumab } \\
\text { pegol }\end{array}$} & \multicolumn{2}{c|}{ Abatacept } & \multicolumn{2}{c|}{ CT-P13 } \\
\hline Time periods, MM.YY & \multicolumn{2}{|c|}{$01.13-06.14$} & $07.14-06.15$ & $07.15-06.16$ \\
\hline Recommended compliance (\%) & \multicolumn{2}{|c|}{80} & \multicolumn{2}{c|}{80} & \multicolumn{2}{c|}{50} \\
\hline Actual compliance to RADS (\%) & \multicolumn{2}{|c|}{71} & \multicolumn{2}{c|}{66} & \multicolumn{2}{c|}{60} \\
\hline Baseline characteristics & RADS & $\begin{array}{c}\text { Not } \\
\text { RADS }\end{array}$ & RADS & $\begin{array}{c}\text { Not } \\
\text { RADS }\end{array}$ & RADS & $\begin{array}{c}\text { Not } \\
\text { RADS }\end{array}$ \\
\hline Number of pts & 328 & 135 & 210 & 109 & 200 & 131 \\
\hline Age (years) & $\mathbf{5 7}$ & $\mathbf{5 8}$ & 57 & 59 & 59 & 56 \\
\hline Female (\%) & $\mathbf{7 1}$ & $\mathbf{8 0}$ & 73 & 71 & 69 & 71 \\
\hline IgM-RF positive (\%) & 61 & 61 & 67 & 69 & 64 & 70 \\
\hline Anti-CCP positive (\%) & 74 & 73 & 77 & 83 & 70 & 71 \\
\hline Disease duration (years) & 3 & 5 & 3 & 4 & 4 & $\mathbf{2}$ \\
\hline DAS28 & $\mathbf{4 . 6}$ & $\mathbf{4 . 3}$ & $\mathbf{4 . 5}$ & $\mathbf{4 . 3}$ & 4.6 & 4.5 \\
\hline HAQ & 1.1 & 1.1 & $\mathbf{1 . 1}$ & $\mathbf{0 . 9}$ & 1.0 & 1.0 \\
\hline Patient global VAS (mm) & $\mathbf{7 0}$ & $\mathbf{5 7}$ & $\mathbf{7 3}$ & $\mathbf{5 3}$ & 69 & 67 \\
\hline Comorbidities $\geq 1(\%)^{*}$ & $\mathbf{2 2}$ & $\mathbf{3 3}$ & $\mathbf{1 6}$ & $\mathbf{2 8}$ & 24 & 20 \\
\hline No. of comorbidities (mean)** & 1.3 & 1.5 & $\mathbf{1 . 2}$ & $\mathbf{1 . 6}$ & 1.3 & 1.4 \\
\hline Hosp. infections $\geq 1$ (\%)*** & 8 & 10 & 7 & 9 & 9 & 9 \\
\hline Variables are medians unless otherwise mentioned. Numbers in bold: p<0.05 for comparison between
\end{tabular}

RADS/not RADS, (Mann Whitney and Chi-square test) "From baseline and 10 years back;

**In pts with $\geq 1$ comorbidity; $\cdots$ From baseline and 1 year back;

Abbreviations: DAS28 Disease activity score in 28 joints; HAQ health assessment questionnaire;

AAS: visual analogue scale

were more heterogeneous than in clinical trials, reflecting routine care. Overall, compliance to recommendations was good. Thus, the national guidelines in Denmark with mandatory choice of the first biological drug may provide an interesting opportunity to study effectiveness of bDMARDs in routine care. This highlights observational studies as a valuable supplement to RCTs.

\section{References:}

[1] The Danish Council for the Use of Expensive Hospital medicines (RADS), http://www.regioner.dk/media/28308/radsfolder-engelsk.pdf.

[2] Hetland ML. Rehumatology 2011;50:69-77.

Disclosure of Interest: K. Grøn Grant/research support from: BMS, B. Glintborg Grant/research support from: Abbvie, M. Nørgaard Grant/research support from: Department of Clinical Epidemiology is involved in studies with funding from various companies as research grants to (and administered by) Aarhus University, Denmark, F. Mehnert Grant/research support from: Department of Clinical Epidemiology is involved in studies with funding from various companies as research grants to (and administered by) Aarhus University, Denmark, M. Østergaard Grant/research support from: Consultation fees from: Abbvie, BMS, Boehringer-Ingelheim, Celgene, Eli-Lilly, Centocor, GSK, Hospira, Janssen, Merck, Mundipharma, Novartis, Novo, Orion, Pfizer, Regeneron, Schering-Plough, Roche, Takeda, UCB, and Wyeth; Research support and grants from: Abbvie, BMS, Janssen and Merck, L. Dreyer Grant/research support from: MSC, UCB, Janssen Pharmaceutical, N. Krogh: None declared, M. Hetland Grant/research support from: Abbvie, BMS, MSD, Orion, Novartis, UCB, Pfizer DOI: 10.1136/annrheumdis-2017-eular.4116

\section{THU0650 THE EFFECT OF ANTI-TNF THERAPY ON WORK PRODUCTIVITY AND ACTIVITY IMPAIRMENT IN PATIENTS WITH RHEUMATOID ARTHRITIS, ANKYLOSING SPONDYLITIS AND PSORIATIC ARTHRITIS OVER ONE YEAR - REAL LIFE DATA FROM THE CZECH BIOLOGICS REGISTRY ATTRA}

J. Zavada $^{1}$, L. Szczukova ${ }^{2}$, K. Pavelka ${ }^{1}$, P. Horák ${ }^{3}$, J. Vencovsky ${ }^{1}$ on behalf of collaborators of the ATTRA registry. ${ }^{1}$ Rheumatology, Institute of Rheumatology, Prague; ${ }^{2}$ Institute of Biostatistics and Analyses, Faculty of Medicine, Masaryk University, Brno; ${ }^{3}$ Internal Medicine, Faculty of Medicine and Dentistry, Palacký University, Olomouc, Czech Republic

Objectives: To assess the effect of anti-TNF therapy on work productivity using the Work Productivity and Activity Impairment-Specific Health Problem (WPAISHP) questionnaire in patients with RA, PSA and AS in the real life setting. In the Czech Republic, anti-TNF-therapy is reimbursed for RA if DAS28 $>5.1$ despite therapy with csDMARDs, for PSA if disease is not "adequately controlled" with cSDMARDs, and for AS if BASDAl $>4$ and CRP/ESR elevated above normal.

Methods: WPAI-SHP scores were collected for all patients enrolled in ATTRA since 2012 at baseline and after 12 months of anti-TNF exposure. Bionäive patients with RA $(n=352)$, AS $(n=442)$ and PSA $(n=133)$ starting anti-TNF therapy with available baseline data on demography, disease duration and physical function, and WPAI-SHP at baseline and at 12 months were included in this analysis. Patients older than 60 years, on maternity leave or students were excluded. Only patients working for pay at baseline were assessed for WPAI-SHP summary scores: absenteeism (mean \% work time missed), presenteeism (mean \% productivity loss at work), overall work impairment (mean \% overall work productivity loss), and activity impairment (mean \% productivity loss in regular activities). Results: Baseline characteristic were significantly different between diagnoses (Table 1). Working status changed significantly only in patients with RA (employed 